\title{
Position-specific isotope modeling of organic micropollutants transformation through different reaction pathways
}

\author{
Jin, Biao; Rolle, Massimo
}

Published in:

Environmental Pollution

Link to article, DOI:

10.1016/j.envpol.2015.11.014

Publication date:

2016

Document Version

Peer reviewed version

Link back to DTU Orbit

Citation (APA):

Jin, B., \& Rolle, M. (2016). Position-specific isotope modeling of organic micropollutants transformation through different reaction pathways. Environmental Pollution, 210, 94-103. https://doi.org/10.1016/j.envpol.2015.11.014

\section{General rights}

Copyright and moral rights for the publications made accessible in the public portal are retained by the authors and/or other copyright owners and it is a condition of accessing publications that users recognise and abide by the legal requirements associated with these rights.

- Users may download and print one copy of any publication from the public portal for the purpose of private study or research.

- You may not further distribute the material or use it for any profit-making activity or commercial gain

- You may freely distribute the URL identifying the publication in the public portal

If you believe that this document breaches copyright please contact us providing details, and we will remove access to the work immediately and investigate your claim 
This is a Post Print of the article published on line $18^{\text {th }}$ December 2015 and printed March 2016 in Environmental Pollution, 210, 94-103. The publishers' version is available at the permanent link: doi:10.1016/j.envpol.2015.11.014

\title{
Position-specific isotope modeling of organic micropollutants transformation through different reaction pathways
}

\author{
Biao Jin ${ }^{*}$ a and Massimo Rolle ${ }^{\mathrm{a}}$ \\ ${ }^{a}$ Department of Environmental Engineering, Technical University of Denmark, Miljøvej \\ Building 113, DK-2800 Kgs. Lyngby, Denmark \\ *Corresponding author phone: +45 45251459; e-mail: bjin@env.dtu.dk
}

\section{Highlights}

- Mechanism-based, position-specific isotope modeling of micropollutants degradation

- Simultaneous description of concentration and primary and secondary isotope effects

- Key features of the model are demonstrated with three illustrative examples

- Model as a tool to explore reaction mechanisms and to design experiments 


\section{Abstract}

2 The degradation of organic micropollutants occurs via different reaction pathways. Compound

3 specific isotope analysis is a valuable tool to identify such degradation pathways in different

4 environmental systems. We propose a mechanism-based modeling approach that provides a

5 quantitative framework to simultaneously evaluate concentration as well as bulk and position-

6 specific multi-element isotope evolution during the transformation of organic micropollutants.

7 The model explicitly simulates position-specific isotopologues for those atoms that experience

8 isotope effects and, thereby, provides a mechanistic description of isotope fractionation

9 occurring at different molecular positions. To demonstrate specific features of the modeling

10 approach, we simulated the degradation of three selected organic micropollutants:

11 dichlorobenzamide (BAM), isoproturon (IPU) and diclofenac (DCF). The model accurately

12 reproduces the multi-element isotope data observed in previous experimental studies.

13 Furthermore, it precisely captures the dual element isotope trends characteristic of different

14 reaction pathways as well as their range of variation consistent with observed bulk isotope

15 fractionation. It was also possible to directly validate the model capability to predict the

16 evolution of position-specific isotope ratios with available experimental data. Therefore, the

17 approach is useful both for a mechanism-based evaluation of experimental results and as a tool to

18 explore transformation pathways in scenarios for which position-specific isotope data are not yet

19 available. 
24 We propose a modeling approach incorporating mechanistic information and predicting 25 concentration and position-specific isotopic evolution during organic micropollutants 26 degradation.

27 Keywords: Organic micropollutants, CSIA, isotope modeling, position-specific isotope 28 fractionation, transformation pathways

29

\section{Introduction}

Numerous synthetic organic compounds are produced annually in vast quantities for industrial manufacturing processes, agricultural use, as well as for human and animal healthcare (Fenner et al., 2013; Schwarzenbach et al., 2010, 2006). These organic compounds and their metabolites are frequently detected at trace levels in fresh water environments and are therefore referred to as organic micropollutants. Organic micropollutants include a wide array of different compounds such as pesticides, herbicides, pharmaceuticals, food additives, and personal care products (Bao et al., 2012; Lapworth et al., 2012; Murray et al., 2010; Pal et al., 2010). With rapid advances in analytical techniques, new micropollutants have been discovered in the environment at a fast pace, causing increasing environmental concern (Carlson et al., 2013; Imfeld and Vuilleumier, 2012; Murray et al., 2010; Pal et al., 2010; Vorkamp et al., 2014). The assessment of the fate of these chemicals in the environment requires knowledge and information on their degradation pathways. However, the conventional approach based on concentration measurements of parent compounds and transformation products is often not conclusive, since a decrease of concentration might also be caused by dilution, sorption and further transformation of metabolites (Durst et al., 2013; Imfeld et al., 2013; Pal et al., 2010). Compound specific isotope 
analysis (CSIA) measures changes in stable isotope ratios of different elements, and represents a valuable tool to study the transformation of various organic contaminants (Elsner, 2010; Elsner et al., 2005). Recent studies have applied CSIA to investigate the transformation of different organic micropollutants (Bashir et al., 2015; Elsayed et al., 2014; Zhang et al., 2014). Different reaction pathways have been characterized by analyzing dual-element stable isotope ratios of the parent compounds in an increasing number of experimental studies (Hartenbach et al., 2008; Maier et al., 2014; Meyer and Elsner, 2013; Penning et al., 2010; Reinnicke et al., 2011) Multielement isotope data obtained from this experimental work provide valuable insights into the degradation mechanisms of organic micropollutants. Isotope models are useful tools to predict and quantitatively evaluate the isotopic evolution during degradation reactions, to link observed isotopic data to specific reaction mechanisms (Hofstetter et al., 2007; Hunkeler et al., 2009; Jin and Rolle, 2014) and to describe isotope fractionation in complex environmental systems where both physical and transformation processes may cause isotope fractionation and affect the observed isotopic signals (Eckert et al., 2012; Jin et al., 2014, 2013; Thullner et al., 2012; Van Breukelen and Rolle, 2012). To date, multi-element isotope modeling studies have focused on widespread groundwater organic contaminants such as chlorinated ethenes, MTBE and BTEX (Centler et al., 2013; Jin and Rolle, 2014). Although multi-element isotope modeling would be beneficial to evaluate isotope data also for different organic micropollutants, such an approach is still lacking for these contaminants. In particular, micropollutants are typically large molecules for which bulk isotope fractionation observed in environmental samples is often significantly diluted. For this reason, position-specific information, which goes beyond bulk isotope ratios typically addressed in CSIA applications, greatly helps to gain insights on the occurrence and on the mechanisms of specific degradation reactions. In this study we aim at presenting and 
validating a multi-element isotope modeling approach that represents a valuable tool for the

69 simultaneous quantitative interpretation of concentration as well as bulk and position-specific

70 isotope data during the degradation of organic micropollutants. The approach builds on the

71 foundations laid in a recent contribution (Jin and Rolle, 2014) that first proposed to incorporate

72 mechanistic and position-specific understanding of contaminant degradation on model-based

73 interpretation of isotope data. Model formulations are proposed in this study to simulate isotope

74 fractionation during degradation of organic micropollutants. Such formulations are independent

75 of commonly adopted linear regressions of dual-element isotope data. They are based on a mass

76 conservation description of degradation reactions that allows incorporating mechanistic

77 knowledge of isotopic evolution for different reaction pathways. The outcomes of the

78 simulations highlight interesting and specific features characterizing micropollutants

79 transformation and constitute a relevant improvement compared to commonly applied modeling

80 approaches that rarely attempt to incorporate mechanistic information.

81 Specifically, the goals of this work are to: (i) present and illustrate multi-element isotope 82 modeling approaches for degradation of organic micropollutants based on position-specific

83 isotopologues which track atoms in positions experiencing isotope effects; (ii) apply the model to 84 predict multi-element isotope changes during degradation of selected important organic 85 micropollutants such as dichlorobenzamide (BAM), isoproturon (IPU) and diclofenac (DCF); (iii) 86 illustrate the capability of the model to describe position-specific isotope fractionation occurring 87 at and close to reacting bonds, to capture both primary and secondary isotope effects and to 88 explore their possible extent of variation consistently with observed bulk isotope data; (iv) 89 directly validate the outcomes of the proposed position-specific isotope modeling with available 90 position-specific isotope data; (v) show the potential of the model as predictive tool to explore 
91 the applicability of CSIA for different elements and degradation scenarios for which an

92 experimental investigation is not (yet) available.

\section{Modeling Approach and Reaction Pathways}

94 Biodegradation of organic micropollutants in the environment can follow different reaction

95 pathways. Since micropollutants often have large and complex molecular structures and their

96 biodegradation involves the cleavage of specific bonds, an efficient way to simulate multi-

97 element isotope fractionation for these compounds is to track position-specific isotopologues,

98 considering atoms at isotopically-sensitive positions. This method represents a convenient

99 balance between a fully-integrated approach (i.e., considering all possible isotopologues) that has

100 been proposed for small molecules such as chlorinated compounds (Jin et al., 2013) and common,

101 simplified, formulations exclusively considering two virtual heavy and light species (e.g., Eckert

102 et al., 2012) and preventing to capture specific characteristics of different degradation pathways.

103 The proposed modeling framework allows incorporating mechanism-specific information in the

104 simultaneous description of concentration and stable isotope evolution during micropollutants

105 transformation. The key steps of the model formulation are to:

106 - hypothesize the degradation reaction mechanisms and identify the fractionating atoms.

107 Important elements for this initial conceptualization step are the insights of experimental

108 investigation, ab-initio calculations and expert judgment;

109 - define position-specific isotopologues, which are a small subset of all possible

110 isotopologues, exclusively containing atoms located at positions experiencing isotope

111 effects. To identify the position specific isotopologues we introduce a "string notation",

112 which, for a dual-isotope system involving two elements $A$ and $B$, reads as: $\left[A_{p, s}-B_{p, s}\right]$, 

where the subscripts $\mathrm{p}$ and $\mathrm{s}$ indicate primary and secondary isotopic positions and the dash represents a chemical bond that may connect the fractionating atoms A and B; - derive the fractionation factors for primary and secondary isotope effects based on corresponding apparent kinetic isotope effects (AKIEs). The latter can be calculated by reported enrichment factors or by directly fitting the model to measured position-specific isotope data;

- track the concentration evolution of each position-specific isotopologue undergoing degradation according to a specified kinetic rate law;

121 - compute the changes of position-specific and bulk isotope ratios.

122 Degradation mechanisms and position-specific isotopologues. To illustrate the proposed 123 modeling approach three examples of micropollutants degradation have been selected. These 124 examples include aerobic degradation of dichlorobenzamide (BAM), biotic hydrolysis of 125 isoproturon (IPU) and aerobic degradation and reductive dechlorination of diclofenac (DCF). 126 The degradation pathways for these compounds are schematically illustrated in Figure 1. 

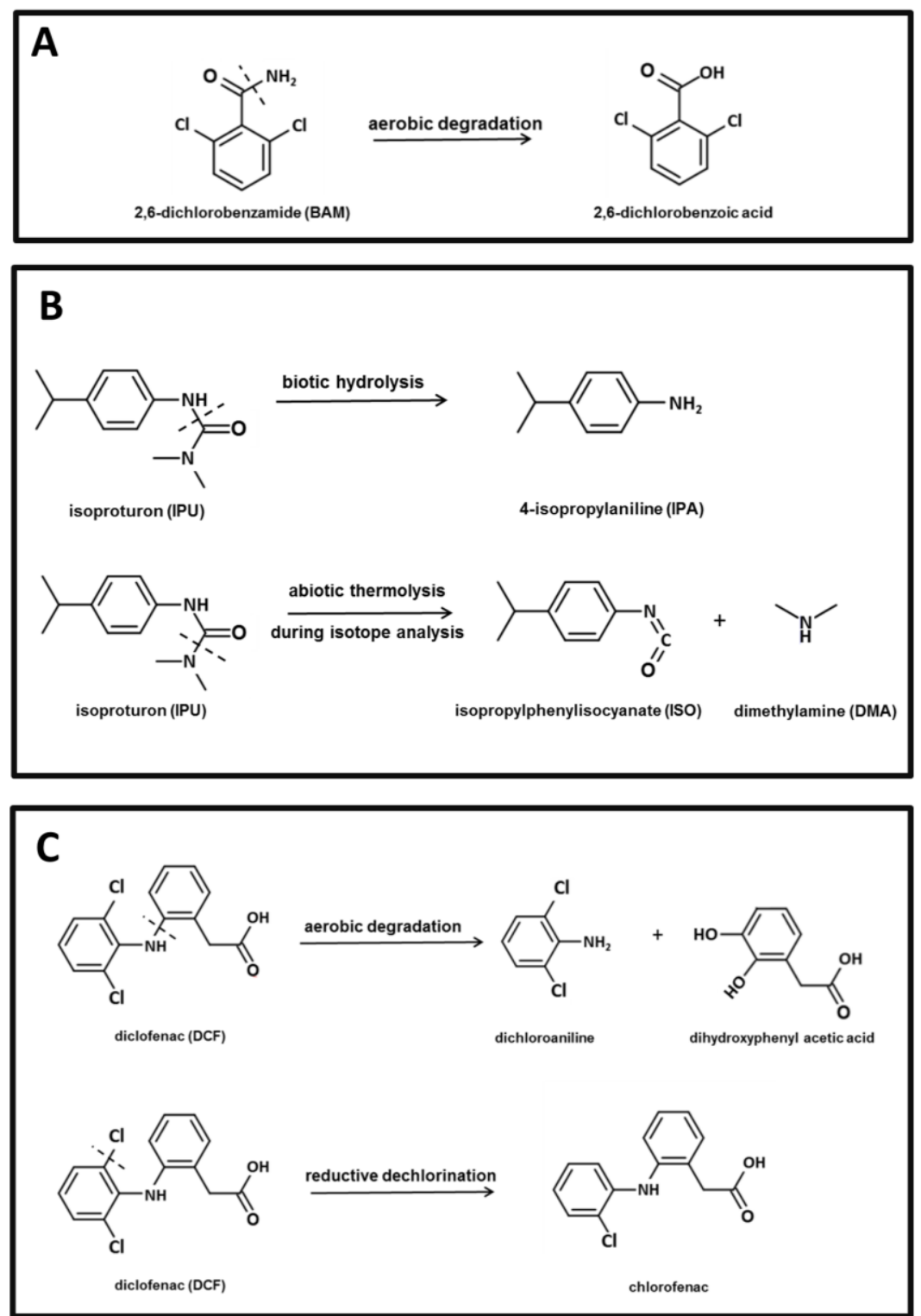

128 Figure 1. Reaction pathways for the selected organic micropollutants. Panel A: aerobic degradation of 129 BAM; Panel B: biotic hydrolysis of IPU and abiotic thermolysis of IPU during compound-specific 130 isotope analysis resulting in two fragments (isopropylphenylisocyanate, ISO, and dimethylamine, DMA) 131 and; Panel C: suggested reaction pathways for aerobic degradation and reductive dechlorination of DCF. 
134 Dichlorobenzamide is an important organic micropollutant. It is the main metabolite of the 135 herbicide 2,6-dichlobenil and, due to its mobility, it is often found in groundwater at 136 concentration levels higher than its parent compound (Holtze et al., 2008). Dual carbon and 137 nitrogen isotope ratios were measured to monitor microbial degradation of BAM (Reinnicke et 138 al., 2011). Significant carbon and nitrogen isotope fractionation were observed during BAM 139 degradation through microbial hydrolysis by two bacterial stains, Aminobacter sp. MSH1 and 140 Aminobacter sp. ASI1. A nucleophilic substitution results in carbon and nitrogen isotope 141 fractionation at the carbonyl carbon as well as at the amide nitrogen. To model this reaction 142 pathway we consider the position-specific isotopologues, $[\mathrm{C}-\mathrm{N}]$, to track the $\mathrm{C}$ and $\mathrm{N}$ atoms in 143 the reactive bond.

144 Isoproturon is used as systemic herbicide in cereal crops and it can be degraded by different 145 reaction pathways such as hydroxylation, N-demethylation and biotic hydrolysis. Among these 146 degradation pathways microbial hydrolysis of IPU is of special interest due to the fact that the 147 metabolite, 4-isopropylaniline, further reacts with soil organic matter, making this pathway 148 difficult to identify in aqueous environments (Barriuso et al., 2008). Biotic hydrolysis of 149 isoproturon by Arthrobacter globiformis D47 involves a complex reaction mechanism and C and $150 \mathrm{~N}$ isotope fractionation occurs at different parts of IPU molecules (Penning et al., 2010). This 151 reaction mechanism causes $\mathrm{C}$ and $\mathrm{N}$ isotope fractionation in different parts of IPU molecules. 152 Results from position-specific isotope analysis of the two thermolysis fragments of isoproturon, 153 isopropylphenylisocyanate (ISO) and dimethylamine (DMA), indicate that the carbonyl carbon 154 and the aryl nitrogen of ISO are at reactive and fractionating positions. The alkyl nitrogen and 155 the two methyl carbon atoms of DMA, instead, are at nonreactive positions but still undergo 156 fractionation due to secondary isotope effects (Penning et al., 2010). In order to track all the 
157 atoms at positions experiencing isotope effects during biotic hydrolysis of isoproturon, we 158 consider the position-specific isotopologues of isoproturon by tracking $\left[\mathrm{N}_{\mathrm{p}}-\mathrm{C}_{\mathrm{p}} \mathrm{C}_{\mathrm{s}}-\mathrm{N}_{\mathrm{s}}-\mathrm{C}_{\mathrm{s}}\right](p$ : 159 positions experiencing primary isotopic effects; $s$ : positions experiencing secondary isotopic 160 effects).

161 As last example of micropollutant degradation we consider the transformation of diclofenac, a 162 widely used painkiller and anti-inflammatory agent. Diclofenac degradation occurs through both 163 aerobic degradation and reductive dechlorination reactions. A very recent study successfully 164 distinguished the two reaction pathways using dual-element C and N CSIA (Maier et al., 2014). 165 and showed different extents of $\mathrm{C}$ and $\mathrm{N}$ isotope fractionation during aerobic degradation and 166 reductive dechlorination. Assuming that a $\mathrm{C}-\mathrm{N}$ bond is cleaved during aerobic degradation of 167 diclofenac, our model tracks $[\mathrm{C}-\mathrm{N}]$ for the position-specific isotopologues of DCF. In the 168 reductive dechlorination of diclofenac, instead, one $\mathrm{C}-\mathrm{Cl}$ bond is cleaved, leading to primary 169 carbon isotope effects at the $\mathrm{C}-\mathrm{Cl}$ position and secondary nitrogen isotope effects at the 170 neighboring nitrogen atom. Thus, for this reaction pathway the model tracks the isotopically171 sensitive atoms [N C-Cl]. Furthermore, a modeling scenario has been carried out to account for 172 possible secondary chlorine isotope fractionation occurring at the chlorine atom adjacent to the 173 reactive $\mathrm{C}-\mathrm{N}$ bond during aerobic degradation of diclofenac. Thus, the isotopically sensitive 174 elements $[\mathrm{N}-\mathrm{C} \mathrm{Cl}]$ have been considered in the simulation of 3D isotope fractionation, providing 175 the simultaneous description of the three elements: C, $\mathrm{N}$ and $\mathrm{Cl}$.

176 The illustrative examples presented in this study, the considered elements and stable isotopes, the 177 reaction kinetics and the position-specific isotopologues used in the simulations are summarized 178 in Table 1. The table shows the main characteristics of the modeling approach and reveals the 179 rationale behind the selection of the illustrative examples. In fact, as summarized in the last 
180 column of the table, each selected micropollutant particularly highlights a specific key feature of

181 the proposed methodology.

182 Table 1. Specific features and information for the mechanistic modeling of the selected 183 micropollutants.

\begin{tabular}{|c|c|c|c|c|}
\hline Compound & Reaction kinetic & Isotope & $\begin{array}{l}\text { Position-specific } \\
\text { isotopologue }\end{array}$ & Key feature \\
\hline $\begin{array}{l}\text { Dichlorobenzimade } \\
\qquad(\mathrm{BAM})\end{array}$ & Michaelis-Menten & $\begin{array}{l}{ }^{13} \mathrm{C} /{ }^{12} \mathrm{C} \\
{ }^{15} \mathrm{~N} /{ }^{14} \mathrm{~N}\end{array}$ & {$\left[\mathrm{C}_{\mathrm{s}}-\mathrm{C}_{\mathrm{p}}-\mathrm{N}\right]$} & $\begin{array}{l}\text { Simulate primary and } \\
\text { secondary isotope effects } \\
\text { on atoms of the same element } \\
\text { and their range of variation }\end{array}$ \\
\hline $\begin{array}{l}\text { Isoproturon } \\
\text { (IPU) }\end{array}$ & first-order & $\begin{array}{l}{ }^{13} \mathrm{C} /{ }^{12} \mathrm{C} \\
{ }^{15} \mathrm{~N} /{ }^{14} \mathrm{~N}\end{array}$ & {$\left[\mathrm{~N}_{\mathrm{p}}-\mathrm{C}_{\mathrm{p}} \mathrm{C}_{\mathrm{s}}-\mathrm{N}_{\mathrm{s}}-\mathrm{C}_{\mathrm{s}}\right]$} & $\begin{array}{l}\text { Describe position-specific } \\
\text { isotope fractionation and } \\
\text { directly compare position- } \\
\text { specific model predictions } \\
\text { with position-specific } \\
\text { isotope data }\end{array}$ \\
\hline $\begin{array}{l}\text { Diclofenac } \\
\text { (DCF) }\end{array}$ & first-order & $\begin{array}{l}{ }^{13} \mathrm{C} /{ }^{12} \mathrm{C} \\
{ }^{15} \mathrm{~N} /{ }^{14} \mathrm{~N} \\
{ }^{37} \mathrm{Cl} /{ }^{35} \mathrm{Cl}\end{array}$ & $\begin{array}{l}{[\mathrm{N} \mathrm{C}-\mathrm{Cl}]} \\
{[\mathrm{N}-\mathrm{C} \mathrm{Cl}]}\end{array}$ & $\begin{array}{l}\text { Explore three-dimensional } \\
\text { isotopic evolution as well as } \\
\text { predict isotope fractionation } \\
\text { for an element }(\mathrm{Cl}) \text { not yet } \\
\text { experimentally investigated }\end{array}$ \\
\hline
\end{tabular}

Governing equations. To illustrate in detail the modeling approach, we select the complex case

186 of biotic hydrolysis of isoproturon. Complete descriptions of the governing equations for the

187 reaction pathways of BAM and DCF degradation are available in the supplementary material. As

188 mentioned above, in order to model $\mathrm{C}$ and $\mathrm{N}$ isotope fractionation during biotic hydrolysis of 189 isoproturon, the isotopically sensitive positions $\left[\mathrm{N}_{\mathrm{p}}-\mathrm{C}_{\mathrm{p}} \mathrm{C}_{\mathrm{s}}-\mathrm{N}_{\mathrm{s}}-\mathrm{C}_{\mathrm{s}}\right]$ need to be tracked. Furthermore, 190 the model considers the isotopic evolution of the two thermolysis fragments of IPU: 191 isopropylphenylisocyanate (ISO) and dimethylamine (DMA), generated by position specific 192 isotope anaylsis of isoproturon (Panel B in Figure 1). Since the occurrence of each nitrogen and 
193 carbon atom of the $j^{\text {th }}$ IPU isotopologue (with isotopically-sensitive atoms $\left[\mathrm{N}_{\mathrm{p}}-\mathrm{C}_{\mathrm{p}} \mathrm{C}_{\mathrm{s}}-\mathrm{N}_{\mathrm{s}}-\mathrm{C}_{\mathrm{s}}\right]$ ) is 194 independent, the relative abundance of the $j^{\text {th }}$ IPU isotopologue is given by the product of the 195 abundance of each isotope:

$$
A_{j}=X_{{ }^{15} N, p}^{v} \cdot X_{{ }^{14} N, p}^{1-v} \cdot X_{{ }^{u} N, s}^{u} \cdot X_{{ }^{14} N, s}^{1-u} \cdot Y_{{ }^{13} C, p}^{i} \cdot Y_{{ }^{12} C, p}^{1-i} \cdot Y_{{ }^{13} C, s}^{h} \cdot Y_{{ }^{2} C, s}^{2-h}
$$

196

197 where $A_{j}$ is the relative abundance of the $j^{\text {th }}$ position-specific isotopologue containing $v{ }^{15} \mathrm{~N}$ 198 isotopes at reactive position (the subscript $p$ represents primary isotopic positions) and $u^{15} \mathrm{~N}$ at 199 nonreactive position (the subscript $s$ represents secondary isotopic positions) as well as $i^{13} \mathrm{C}$ 200 isotopes at reactive positions and $h{ }^{13} \mathrm{C}$ isotopes at nonreactive positions. $X$ and $Y$ are the 201 abundances of $\mathrm{N}$ and $\mathrm{C}$ isotopes, respectively.

202 The carbon and nitrogen isotopes of isopropylphenylisocyanate (ISO) and dimethylamine 203 (DMA) are fractionating according to the corresponding apparent kinetic isotope effects (AKIEs), 204 which can be expressed as (Elsner et al., 2005):

$$
\begin{aligned}
& \alpha_{C, p}=A K I E_{C, p}^{-1} \approx 1+10 \cdot \varepsilon_{C, I S O} \\
& \alpha_{C, s}=A K I E_{C, s}^{-1} \approx 1+\varepsilon_{C, D M A} \\
& \alpha_{N, p}=A K I E_{N, p}^{-1} \approx 1+\varepsilon_{N, I S O} \\
& \alpha_{N, s}=A K I E_{N, s}^{-1} \approx 1+\varepsilon_{N, D M A}
\end{aligned}
$$

205 where $\alpha$ is the fractionation factor for primary or secondary isotope effects, $\varepsilon$ is the bulk 206 enrichment factor of ISO or DMA. The factor 10 in Eq. (2) is the ratio between the total number 207 of carbon atoms and the number of the fractionating carbon atoms in ISO molecules. In the other 208 equations this factor is 1 since all the atoms tracked experience isotope effects. Considering first209 order kinetics, the reaction rate for the $j^{\text {th }}\left[\mathrm{N}_{\mathrm{p}}-\mathrm{C}_{\mathrm{p}} \mathrm{C}_{\mathrm{s}}-\mathrm{N}_{\mathrm{s}}-\mathrm{C}_{\mathrm{s}}\right]$ isotopologue of IPU is given as:

$$
r_{j}=-k \cdot\left(\alpha_{N, p}\right)^{v} \cdot\left(\alpha_{N, s}\right)^{u} \cdot\left(\alpha_{C, p}\right)^{i} \cdot\left(\alpha_{C, s}\right)^{h} \cdot C_{j}
$$


211 where $r_{j}$ is the reaction rate for the position-specific isotopologue, $k$ is the first-order reaction rate

212 constant of the isotopologue containing only light isotopes, $C_{j}$ is the concentration of the $j^{\text {th }}$

213 position-specific isotopologue and $\alpha$ is the fractionation factor defined in Eqs. (2-5).

214 The concentration change of isoproturon is described by tracking each position-specific 215 isotopologue:

$$
\frac{d C_{I P U, j}}{d t}=r_{j}
$$

217 where $C_{I P U, j}$ is the concentration of the $j^{\text {th }}$ position-specific isotopologue of IPU, $t$ is the time, and $218 r_{j}$ is the reaction rate of the $j^{\text {th }}$ position-specific isotopologue. The total concentration of IPU is 219 obtained by summing the concentration of each isotopologue: $C_{I P U}=\sum_{j} C_{I P U, j}$.

220 The computed concentration of each position-specific isotopologue is used to calculate the 221 carbon and nitrogen isotope ratios of isopropylphenylisocyanate (ISO) and dimethylamine 222 (DMA) by counting the total number of heavy and light carbon and nitrogen isotopes, 223 respectively (Jin et al., 2011). Moreover, it is necessary to account for the dilution by the nine 224 non-fractionating carbon atoms in ISO, whereas the bulk nitrogen isotope ratios of ISO and 225 DMA are the same as the corresponding position-specific isotope ratios since there is no nitrogen 226 atom at non-fractionating position. Thus, the bulk isotope ratios for the two thermolysis products 227 of isoproturon can be computed as: 


$$
\begin{gathered}
R_{C, I S O}=\frac{\operatorname{tot}\left({ }^{13} C\right)}{\operatorname{tot}\left({ }^{12} C\right)}=\frac{1}{10} \cdot \frac{\sum_{j=1}^{n} i \cdot C_{j}}{\sum_{j=1}^{n}(1-i) \cdot C_{j}}+\frac{9}{10} \cdot R_{C, 0} \\
R_{C, D M A}=\frac{\operatorname{tot}\left({ }^{13} C\right)}{\operatorname{tot}\left({ }^{12} C\right)}=\frac{\sum_{j=1}^{n} h \cdot C_{j}}{\sum_{j=1}^{n}(1-h) \cdot C_{j}} \\
R_{N, I S O}=\frac{\operatorname{tot}\left({ }^{15} N\right)}{\operatorname{tot}\left({ }^{14} N\right)}=\frac{\sum_{j=1}^{n} v \cdot C_{j}}{\sum_{j=1}^{n}(1-v) \cdot C_{j}} \\
R_{N, D M A}=\frac{\operatorname{tot}\left({ }^{15} N\right)}{\operatorname{tot}\left({ }^{14} N\right)}=\frac{\sum_{j=1}^{n} u \cdot C_{j}}{\sum_{j=1}^{n}(1-u) \cdot C_{j}}
\end{gathered}
$$

228 where $R_{C}$ and $R_{N}$ are the $\mathrm{C}$ and $\mathrm{N}$ isotope ratios of ISO or DMA, $C_{j}$ is the concentration of the $j^{\text {th }}$ 229 position-specific isotopologue of IPU, DMA or ISO, $R_{0, C}$ is the initial carbon isotope ratio. 230 Equation 8 for $R_{C, I S O}$ is given under the assumption that secondary isotope effects are only 231 occurring in the DMA fragment. Since bulk isotope ratios are measured and reported in most 232 isotope applications, our model can also predict bulk carbon and nitrogen isotope ratios of 233 isoproturon. This is done by taking the weighted mean of the isotope ratios of both ISO and 234 DMA:

$$
\begin{gathered}
R_{C, I P U}=\frac{10}{12} \cdot R_{C, I S O}+\frac{2}{12} \cdot R_{C, D M A} \\
R_{N, I P U}=\frac{1}{2} \cdot R_{N, I S O}+\frac{1}{2} \cdot R_{N, D M A}
\end{gathered}
$$


236 where $R_{C}$ and $R_{N}$ are the bulk $\mathrm{C}$ and $\mathrm{N}$ isotope ratios of ISO, DMA or IPU, respectively. The

237 weighting factors represent the number of carbon or nitrogen atoms in ISO or DMA fragments

238 which are weighted by the total number of carbon and nitrogen atoms in IPU.

239

240

241

242

243

244

245

246

247

248

249

250

251

252

253

254

255

256 257 isotope ratios at the $\mathrm{C}-\mathrm{N}$ position has the same extent as the bulk nitrogen isotope ratios, since 258

\section{Results and Discussion}

2,6-dichlorobenzamide (BAM) degradation. The results of the multi-element isotope modeling of BAM degradation are reported in Figure 2 where they are also compared with the experimental data of Reinnicke et al. (2012). The experimental study (Reinnicke et al., 2012) investigated biotic hydrolysis of diclorobenzamide by two microbial strains Aminobacter $s p$. MSH1 and Aminobacter sp. ASI1. The data (symbols in Fig. 2A) show a similar extent of C isotope fractionation for both strains ( 22\%). However, strain MSH1 showed slightly stronger $\mathrm{N}$ isotope fractionation (-11.7 to 26.5\%) compared with ASI1 (-11.6 to $16.4 \%$ ). The solid lines in Fig. 2A represent the multi-element isotope modeling results, which accurately capture the observed $\mathrm{C}$ and $\mathrm{N}$ isotope fractionation. Similar but distinguishable dual-isotope plots are observed for both strains, suggesting similar transformation mechanisms for BAM biotic hydrolysis. The model implements the experimental observations suggesting that $\mathrm{C}$ and $\mathrm{N}$ isotope fractionation occurs due to the cleavage of the $\mathrm{C}-\mathrm{N}$ bond and considers position-specific isotopologues of BAM by tracking the atoms contained in the reacting bond [C-N]. The outcomes of the model can be expressed as shifts both in bulk and position-specific isotope ratios. The latter are a direct result of the model, which simulates the cleavage of the $\mathrm{C}-\mathrm{N}$ bond and thus the position-specific $\mathrm{C}$ and $\mathrm{N}$ isotope fractionation at the carbonyl carbon atom and the amide nitrogen atom, respectively. These results are reported in Fig. $2 \mathrm{~B}$ and show that the variation in there is only one nitrogen atom in BAM molecules. However, the shift of the undiluted position- 

-26.3 to $139.9 \%$.
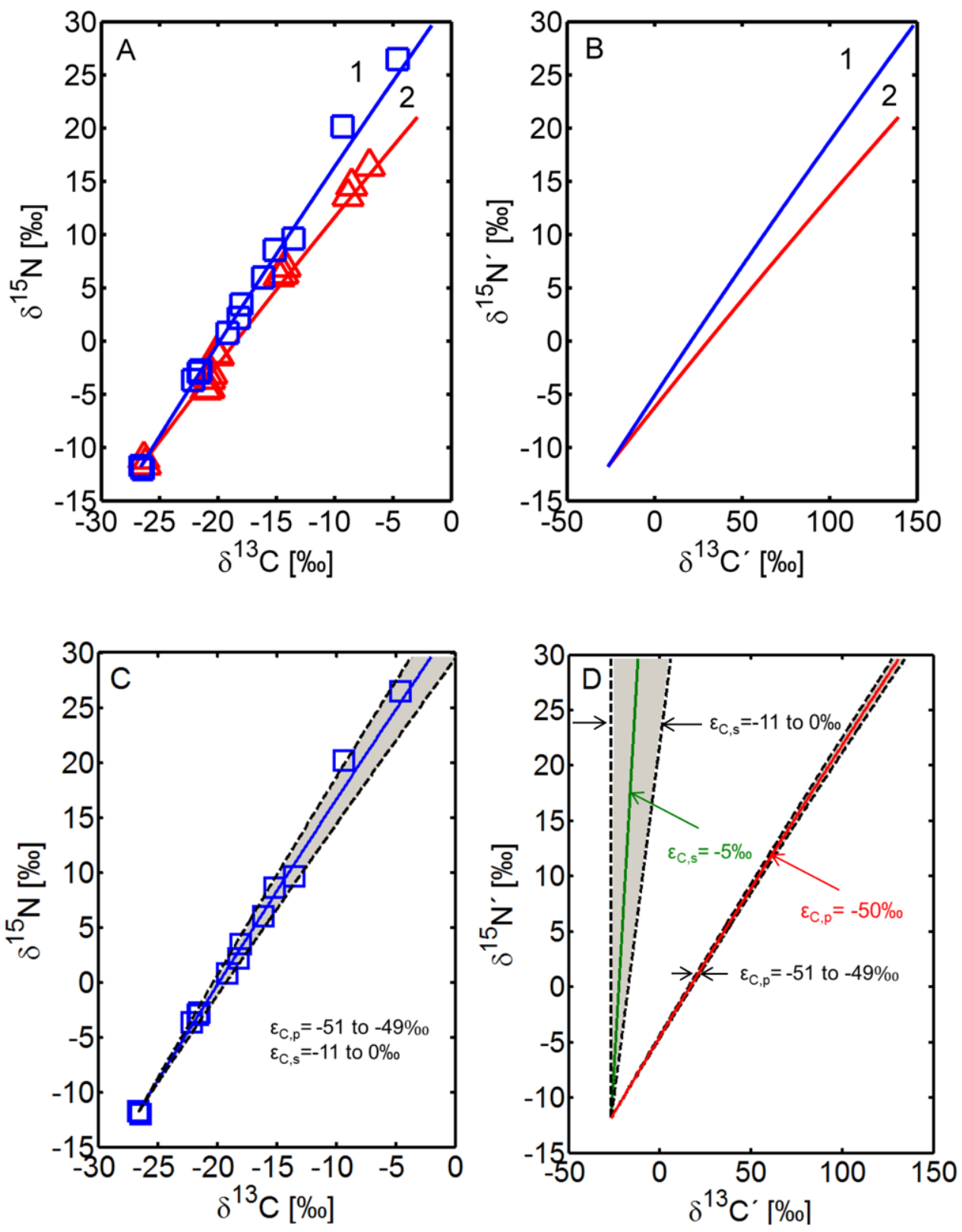

Figure 2. Carbon and nitrogen isotope fractionation during microbial hydrolysis of dichlorobenzamide (BAM). The symbols represent the experimental data reported by Reinnicke et al., 2012, and the solid lines are the simulation results. The numbers in Panels A and B indicate the degradation by two different microbial strains (1: Aminobacter sp. MSH1, 2: Aminobacter sp. ASI1). Panel B shows the position- 
respectively. Panel $\mathrm{C}$ shows the simulation results for the scenario in which carbon isotope fractionation occurs on both C-N position and on the neighboring carbon atom; the dashed lines represent the range of variation of primary $\left(\varepsilon_{C, p}^{\prime}\right.$ from -51 to $\left.-49 \%\right)$ and secondary $\left(\varepsilon_{C, s}^{\prime}\right.$ from -11 to $0 \%$ ) isotope effects consistent with the experimental data. The corresponding dual-isotope plots for primary and secondary isotope effects at the fractionating positions are reported in Panel D.

Besides illustrating our modeling approach for the interpretation of the experimental data for BAM degradation, we used numerical simulations to explore the magnitude of secondary isotope effects. Isotope fractionation due to secondary isotope effects has been observed during the degradation of different organic contaminants (Hofstetter et al., 2008; Kuder et al., 2013) but, to date, it has not been reported for BAM degradation. We performed simulations to estimate the effects of $\mathrm{C}$ isotope fractionation occurring at both reactive and nonreactive positions during BAM degradation. We considered the scenario in which both primary and secondary $\mathrm{C}$ isotope effects occur on the $\mathrm{C}-\mathrm{N}$ position as well as on the neighboring carbon atom. The model formulation for BAM degradation was modified to include secondary isotope effects and to track $\left[\mathrm{C}_{\mathrm{s}}-\mathrm{C}_{\mathrm{p}}-\mathrm{N}\right]$ isotopologues ( $p$ : position experiencing primary isotopic effects; $s$ : position experiencing secondary isotopic effects). The simulation results for biotic hydrolysis of BAM by Aminobacter sp. MSH1 (reaction pathway 1) are reported in panel C and D of Figure 2. A number of simulations were performed spanning all possible combinations of primary and secondary isotope effects resulting in bulk $\mathrm{C}$ enrichment factors consistent and within the range of uncertainty of the experimental data (Fig. 2C). Isotope effects at fractionating positions are reported in Fig. 2D; the outcomes of the simulations based on possible values of primary and secondary enrichment factors are shown as shaded areas. The trends shown in Fig. 2D help visualizing the important contribution of both primary and secondary isotope effects at specific positions of BAM molecules. The primary carbon isotope fractionation at $\mathrm{C}-\mathrm{N}$ position occurs according to an enrichment factor, $\varepsilon_{C, p}^{\prime}$, in a range between -51 and $-49 \%$, which is similar and only slightly lower than the Streitwieser limit for cleavage of a C-N bond (Cook, 1991). The 
293 position-specific enrichment factor, $\varepsilon_{C, s}$, at the neighboring position, $C_{s}$, was varied from -11 to

$2940 \%$ to account for different possible extents of secondary isotope effects. The selected values of 295 enrichment factors at $C_{p}$ and $C_{s}$ positions caused primary isotope fractionation varying from 29626.6 to $134.3 \%$ as well as significant position-specific isotope fractionation at secondary isotope 297 positions in a range between -26.6 and $6.0 \%$.

298 Isoproturon degradation. Multi-element isotope analysis has been used to investigate microbial 299 hydrolysis of isoproturon (Penning et al., 2010). Such reaction mechanism yields different 300 extents of carbon and nitrogen isotope fractionation. Furthermore, in that experimental study 301 position-specific isotope analysis was performed to resolve isotope ratio changes in different 302 parts of the isoproturon molecule (i.e. ISO and DMA fragments, Fig. 1). Following a common 303 procedure, the position-specific enrichment factor and AKIE of IPU can be calculated from the 304 measured bulk enrichment factor:

$$
\begin{aligned}
& A K I E_{C, p}^{-1} \approx 1+\varepsilon_{C, I P U}^{\prime}=1+12 \cdot \varepsilon_{C, I P U} \\
& A K I E_{N, p}^{-1} \approx 1+\varepsilon_{N, I P U}^{\prime}=1+2 \cdot \varepsilon_{N, I P U}
\end{aligned}
$$
where $\varepsilon^{\prime}$ is the position-specific enrichment factor and $\varepsilon$ is the bulk enrichment factor of 307 isoproturon. The calculated values AKIE and $\varepsilon$ ' for IPU are reported in Table 2 together with the 308 experimentally evaluated values for the fragments ISO and DMA. It can be noticed that IPU 309 shows considerably higher position-specific enrichment factor and AKIE compared to the values 310 directly determined for ISO and DMA. The reason of this inconsistency is that Eqs. 14 and 15 311 are based on the assumption that secondary isotope effects occurring at non-reactive position do 312 not contribute to the overall bulk isotope fractionation. However, this is proved not to be the case 313 for this degradation pathway, since isotope fractionation observed for DMA clearly shows the 
314 occurrence of secondary isotope effects at the nonreactive positions. Therefore, we applied Eqs

$315 \quad 2-5$ to quantify separately primary and secondary isotope effects for both $\mathrm{C}$ and $\mathrm{N}$. This results in

316 more accurate AKIEs that are suitable to be used as model input parameters to simulate the

317 isotope evolution during microbial hydrolysis of isoproturon. Alternatively, accurate position-

318 specific AKIE values can be directly obtained with the proposed mechanistic modeling approach

319 by fitting the model to the position-specific isotope data.

321 Table2. Evaluation of position-specific enrichment factors $\left(\varepsilon^{\prime}\right)$ and AKIE values of IPU, ISO and DMA

322 for biotic hydrolysis of isoproturon.

\begin{tabular}{|c|c|c|c|c|c|c|}
\hline Compound & Isotope & $n^{\dagger}$ & $x^{*}$ & $\varepsilon_{\text {bulk }}{ }^{*}(\% \mathbf{0})$ & $\varepsilon^{\prime}(\%)$ & AKIE \\
\hline \multirow[t]{2}{*}{ IPU } & $\mathrm{C}$ & 12 & 1 & -5.3 & -63.6 & 1.068 \\
\hline & $\mathrm{N}$ & 2 & 1 & -4.2 & -8.4 & 1.008 \\
\hline \multirow[t]{2}{*}{ ISO } & $\mathrm{C}$ & 10 & 1 & -5.5 & -55 & 1.058 \\
\hline & $\mathrm{N}$ & 1 & 1 & -3.7 & -3.7 & 1.004 \\
\hline \multirow[t]{2}{*}{ DMA } & $\mathrm{C}$ & 2 & 2 & -1.8 & -1.8 & 1.002 \\
\hline & $\mathrm{N}$ & 1 & 1 & -4.8 & -4.8 & 1.005 \\
\hline
\end{tabular}

323

324 Numerical simulations were performed to illustrate the capability of the model to correctly 325 reproduce the observed dual-element $(\mathrm{C}$ and $\mathrm{N})$ isotope fractionation during IPU microbial 326 hydrolysis. Moreover, the experimental dataset offers a unique opportunity to test the capability 327 of the model to predict position-specific isotope fractionation since, as mentioned above, 328 position-specific isotope effects were resolved for the two thermolysis fragments of isotproturon: 329 isopropylphenylisocyanate (ISO) and dimethylamine (DMA). The simulation results and their 330 comparison with the experimental data are shown in Fig. 3. The model is able to simultaneously 331 reproduce the concentrations of isoproturon and its degradation product (4-isopropylaniline) as 
332 well as the measured dual isotope data. The latter include the $\mathrm{C}$ and $\mathrm{N}$ isotope ratios observed for 333 IPU as well as for the thermolysis fragments (ISO and DMA) produced during compound 334 specific isotope analysis. Carbon and nitrogen isotope fractionation occurred at different extents 335 for IPU, DMA and ISO and results in different trends and slopes in a dual-isotope plot (Fig. 3B). $336 \delta^{13} \mathrm{C}$ values varied from -33.3 to $-29.8 \%$ for ISO, -29.7 to $-18.34 \%$ o for DMA and -30.4 to $-18.5 \%$ o 337 for IPU; $\delta^{15} \mathrm{~N}$ ranged from 0.3 to $13.1 \%$ for ISO, -5.0 to $3.8 \%$ for DMA and -7.4 to $-2.6 \%$ for 338 IPU. In particular, the different extents of $\mathrm{C}$ and $\mathrm{N}$ isotope fractionation observed for ISO and 339 DMA fragments, clearly indicate that isotope fractionation involves the atoms at both reactive 340 and nonreactive positions. Specifically, the cleavage of the bond between the carbonyl carbon 341 and the alkyl nitrogen of IPU results in primary carbon and nitrogen isotope effects in ISO. 342 Moreover, secondary isotope effects occur at the alkyl nitrogen and the two methyl carbons of 343 DMA. Thus, $\mathrm{C}$ and $\mathrm{N}$ isotope fractionation of IPU is the sum of primary and secondary isotope 344 effects occurring at ISO and DMA parts of IPU. Interestingly, the carbon isotope fractionation of 345 DMA is only slightly smaller than the one of ISO, even though primary carbon isotope effects 346 occur in the ISO fragment rather than in DMA. The reason for this effect is that carbon isotope 347 fractionation occurring at the carbonyl carbon of ISO is diluted by the nine non-reactive carbon 348 atoms in ISO. The outcomes of the mechanistic model are able to accurately reproduce the dual349 isotope data of IPU, ISO and DMA. This substantiates that the proposed modeling approach 350 correctly describes the reaction mechanism leading to the dual isotope evolution observed in the 351 degradation experiments. 

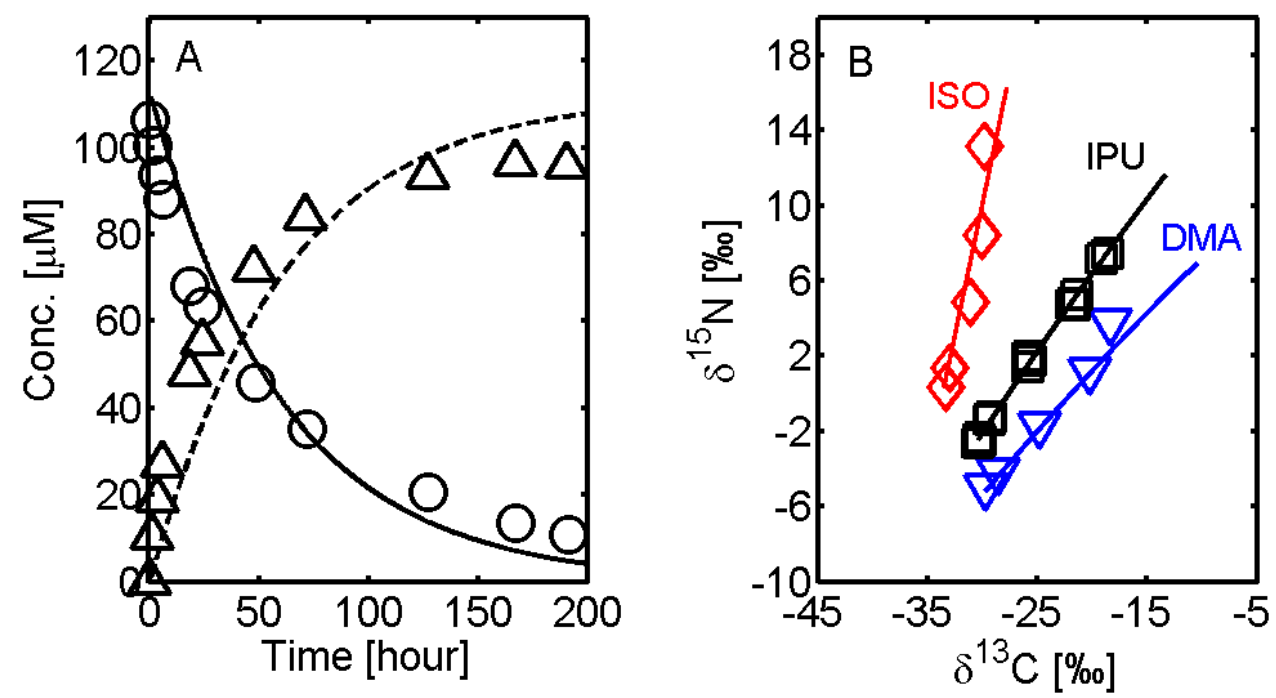

354

355

356

357

358

359

360

361

362

363

364

365

366

367

368

369

370

Figure 3. Concentration changes and carbon and nitrogen isotope fractionation during biotic hydrolysis of isoproturon (IPU). The symbols represent the experimental data reported by Penning et al., 2010, and the lines are the simulation results. In panel A the circles represent the concentration of IPU and triangles are the concentration of the hydrolysis product, 4-isopropylaniline. Panel B shows $\mathrm{C}$ and $\mathrm{N}$ isotope fractionation of IPU (squares) and the thermolysis fragments ISO (diamonds) and DMA (triangles).

Diclofenac (DCF) degradation. The third illustrative example focuses on diclofenac degradation. Both aerobic degradation and reductive dechlorination are important degradation pathways for diclofenac and have been found to yield significantly different extents of carbon and nitrogen isotope fractionation (Maier et al., 2014). To reproduce the isotopic data observed during DCF degradation, we simulated the carbon and nitrogen isotopic evolution during aerobic degradation (according to the suggested reaction pathway 1 reported in Fig. 4A) and reductive dechlorination (according to the reaction pathway 2 reported in Fig. 4A). The model (solid line in Fig. 4A) reproduces the experimental data (symbols in Fig. 4A), which are quite distinct for the two reaction mechanisms. In fact, aerobic degradation was accompanied by strong nitrogen isotope fractionation $(-0.1$ to $10.3 \%$ ), but only small carbon isotope fractionation (-26.5 to 25.0\%o). Conversely, reductive dechlorination showed significant carbon but almost no nitrogen 
371 isotope fractionation. As observed in the previous cases, the model also provides the position372 specific fractionation of both $\mathrm{C}$ and $\mathrm{N}$ (Fig. 4B). The aerobic degradation involves isotope 373 fractionation at $\mathrm{C}-\mathrm{N}$ position, where $\delta^{15} \mathrm{~N}^{\prime}$ shifted from -0.1 to $-10.3 \%$ and $\delta^{13} \mathrm{C}^{\prime}$ varied from 37426.5 to $-18.4 \%$. Conversely, the cleavage of one $\mathrm{C}-\mathrm{Cl}$ bond occurs during $\mathrm{DCF}$ reductive 375 dechlorination, resulting in primary carbon isotope shifts at $\mathrm{C}-\mathrm{Cl}$ position (-25.5 to $11.8 \%$ ) and 376 secondary isotope shifts at the neighboring nitrogen atom (4.0 to 5.3\%o). The two reaction 377 pathways involve carbon atoms at two different positions, and different extents of corresponding 378 position-specific carbon isotope fractionation are observed.

379 Reductive dechlorination of chlorinated organic contaminants involves the cleavage of C-Cl 380 bonds; thus, Cl-CSIA is also of interest to elucidate the underlying reaction mechanisms and has 381 been applied to investigate the degradation of different organic compounds such as chlorinated 382 ethenes and ethanes (Cretnik et al., 2013; Hofstetter et al., 2007; Kuder et al., 2013; Palau et al., 383 2014). Even though no chlorine isotope data is available yet for diclofenac degradation, we 384 performed simulations to predict the possible evolution of $\mathrm{Cl}$ isotopes. This scenario modeling 385 was carried out to explore the potential of chlorine CSIA and required developing a 3D isotope modeling approach to simultaneously simulate $\mathrm{C}, \mathrm{N}$ and $\mathrm{Cl}$ isotope fractionation. For the reactive 387 dechlorination pathway, the bulk chlorine enrichment factors for DCF were selected in a range (3885.4 to $-4.1 \%$ ) from the reported chlorine AKIE values observed during microbial reductive 389 dechlorination of TCE (Cretnik et al., 2013). Concerning aerobic degradation of DCF, even if 390 chlorine atoms are not at reactive positions, they might still fractionate due to secondary chlorine 391 isotope effects. Since secondary chlorine isotope effects result in much smaller chlorine isotope 392 fractionation, we used bulk chlorine isotope enrichment factor of -0.5 to $-0.4 \%$ (estimated to be $3931 / 10$ of the primary chlorine isotope fractionation during reductive dechlorination of TCE) for 
chlorine AKIE. As shown in Fig. 4C, the chlorine isotope signatures varied from 0 to $4.5 \%$ for reductive dechlorination but very small chlorine isotope fractionation, 0 to $0.45 \%$, was predicted for aerobic DCF degradation. The differences between the two reaction pathways predicted by the position-specific modeling scenarios are remarkable and indicate the potential also of chlorine CSIA to distinguish aerobic degradation and reductive dechlorination of DCF.
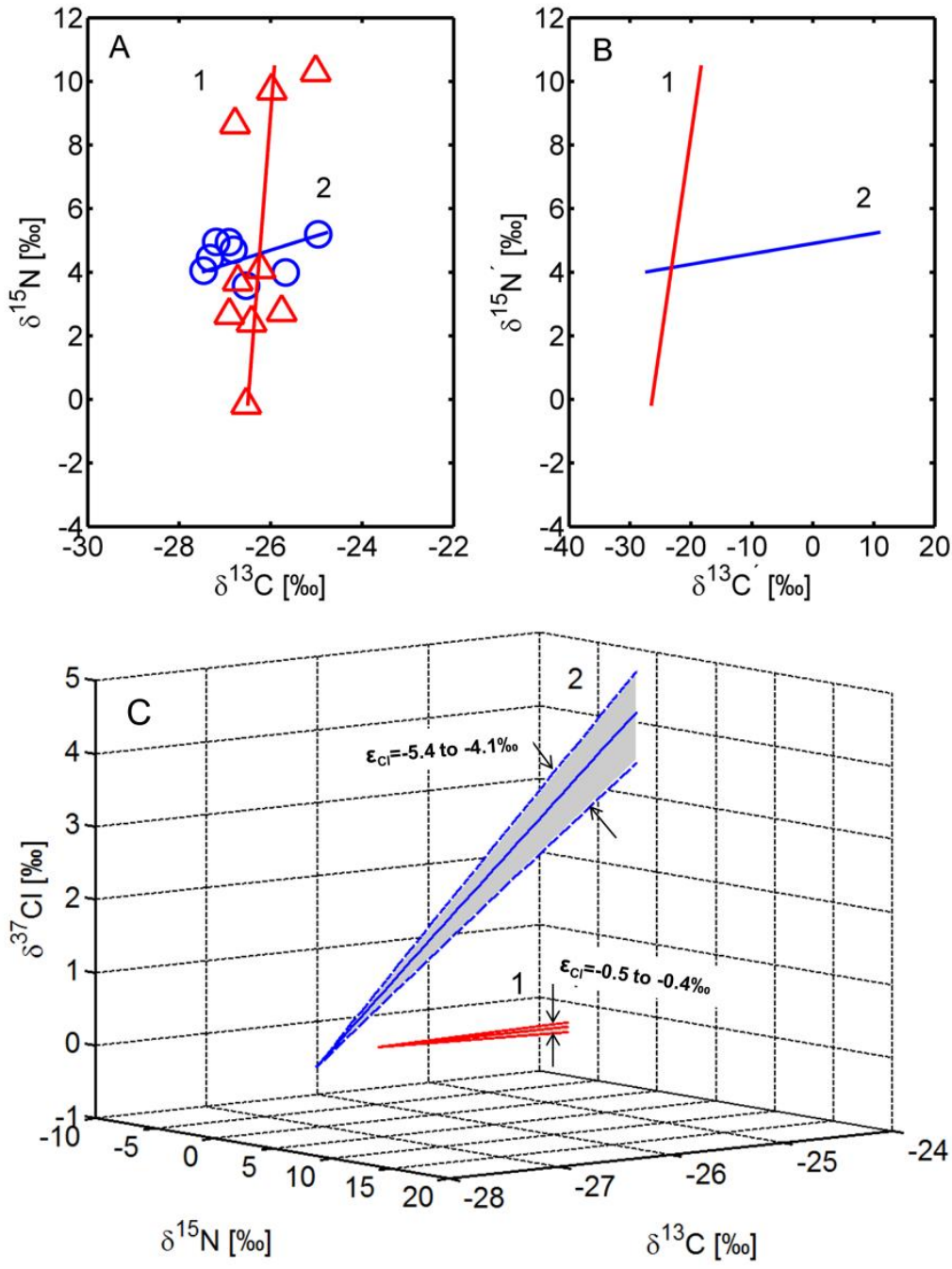

Figure 4. Carbon and nitrogen isotope fractionation during aerobic degradation (reaction pathway 1, red) and reductive dechlorination (reaction pathway 2, blue) of diclofenac (DCF). The symbols represent the experimental data reported by Maier et al., 2014 and the solid lines are the simulation results. Panel B shows the position-specific $\mathrm{C}$ isotope fractionation at $\mathrm{C}-\mathrm{N}$ and $\mathrm{C}-\mathrm{Cl}$ positions and the corresponding position-specific $\mathrm{N}$ isotope fractionation. Panel $\mathrm{C}$ shows the outcomes of the simulation scenarios using the $3 \mathrm{D}$ isotope modeling approach, also including $\mathrm{Cl}$ isotope fractionation. 


\section{Conclusions}

408 Organic micropollutants have been increasingly detected in freshwater environments.

409 Understanding the fate and transport of these trace organic contaminants remains a major

410 challenge. Multi-element CSIA offers important advantages to characterize different reaction

411 pathways and to elucidate reaction mechanisms of organic micropollutants degradation.

412 In this study we have presented a position-specific isotope modeling approach that is useful to 413 quantitatively interpret multi-element isotopic evolution occurring during different 414 transformation pathways of organic micropollutants. The proposed modeling approach 415 simultaneously simulates concentration and multi-element isotope data and allows simulating 416 both bulk and position-specific isotopic evolution. The approach has been validated with three

417 illustrative examples of organic micropollutants degradation including 2,6-dichlorobenzamide, 418 isoproturon and diclofenac. The simulation results could accurately capture the observed isotopic 419 fractionation during the degradation of these micropollutants through different and fairly 420 complex reaction pathways. Furthermore, the proposed modeling approach directly tracks

421 isotopically-sensitive atoms in position-specific isotopologues and thus enables the possibility to 422 simulate both position-specific and bulk isotope evolution. This capability is important since 423 CSIA typically addresses changes of bulk isotope ratios, from which it is challenging to 424 distinguish between primary and secondary isotope effects. As a result, secondary isotope effects 425 are often neglected by assuming that only the cleavage of a chemical bond is contributing to the 426 observed isotope fractionation. However, secondary isotope fractionation might be significant in 427 particular for large organic molecules. Disregarding these effects might lead to an overestimation 428 of AKIE values. To this end, the model represents a valuable instrument that allows considering 
429 possible combinations of both primary and secondary isotope effects thus representing an 430 important tool to evaluate experimental data and to explore and test different mechanistic

431 scenarios. Another advantage, offered by the capability of the model to simulate position-specific

432 isotope fractionation, is the possibility to directly compare the model outcomes with the results

433 of position-specific isotope analysis, a technique that is likely to see an increasing number of

434 applications due to the fast advances of analytical techniques (e.g. Breider and Hunkeler, 2011;

435 Mckelvie et al., 2010; Wuerfel et al., 2013). Finally, besides the assistance in the quantitative

436 interpretation of existing experimental observations, the model can be used to evaluate scenarios

437 not yet explored experimentally as well as to design new experiments. For instance, this

438 capability was illustrated in the case of biodegradation of diclofenac, for which predictive

439 simulations of chlorine isotope fractionation have been performed. This will allow the fast

440 screening of different experimental conditions and reaction mechanisms and may help in

441 selecting the most promising experimental setups and isotope techniques to investigate important

442 reaction pathways and contribute to advance the understanding of micropollutants degradation in

443 different environmental systems.

\section{Acknowledgements}

445 We would like to acknowledge Dr. Martin Elsner (Helmholtz Center Munich) for the 446 experimental data and for insightful comments on an earlier version of the manuscript. This 447 study is supported by the Deutsche Forschungsgemeinschaft (Grant RO4169/2-1). Useful 448 comments and suggestions of three anonymous reviewers helped improving the quality of the 449 manuscript. 


\section{References}

462

463

464

465

466

467

468

469

470

471

472

473

474

475

476

481

482

483

Bao, L.-J., Maruya, K. a., Snyder, S. a., Zeng, E.Y., 2012. China's water pollution by persistent organic pollutants. Environ. Pollut. 163, 100-108. doi:10.1016/j.envpol.2011.12.022

Barriuso, E., Benoit, P., Dubus, I.G., 2008. Formation of Pesticide Nonextractable (Bound) Residues in Soil: Magnitude, Controlling Factors and Reversibility. Environ. Sci. Technol. 42, 1845-1854. doi:10.1021/es7021736

Bashir, S., Hitzfeld, K.L., Gehre, M., Richnow, H.H., Fischer, A., 2015. Evaluating degradation of hexachlorcyclohexane $(\mathrm{HCH})$ isomers within a contaminated aquifer using compound-specific stable carbon isotope analysis (CSIA). Water Res. 71, 187-196. doi:10.1016/j.watres.2014.12.033

Breider, F., Hunkeler, D., 2011. Position-specific carbon isotope analysis of trichloroacetic acid by gas chromatography/isotope ratio mass spectrometry. Rapid Commun. Mass Spectrom. 25, 3659-3665. doi: $10.1002 / \mathrm{rcm} .5276$

Carlson, J.C., Anderson, J.C., Low, J.E., Cardinal, P., MacKenzie, S.D., Beattie, S. a., Challis, J.K., Bennett, R.J., Meronek, S.S., Wilks, R.P. a, Buhay, W.M., Wong, C.S., Hanson, M.L., 2013. Presence and hazards of nutrients and emerging organic micropollutants from sewage lagoon discharges into Dead Horse Creek, Manitoba, Canada. Sci. Total Environ. 445-446, 64-78. doi:10.1016/j.scitotenv.2012.11.100

Centler, F., Heße, F., Thullner, M., 2013. Estimating pathway-specific contributions to biodegradation in aquifers based on dual isotope analysis: Theoretical analysis and reactive transport simulations. J. Contam. Hydrol. 152, 97-116. doi:10.1016/j.jconhyd.2013.06.009

Cook, P., n.d. Enzyme Mechanism from Isotope Effects, 1991st ed. CRC Press, Florida.

Cretnik, S., Thoreson, K. a., Bernstein, A., Ebert, K., Buchner, D., Laskov, C., Haderlein, S., ShouakarStash, O., Kliegman, S., McNeill, K., Elsner, M., 2013. Reductive dechlorination of TCE by chemical model systems in comparison to dehalogenating bacteria: Insights from dual element isotope analysis $(13 \mathrm{C} / 12 \mathrm{C}, 37 \mathrm{Cl} / 35 \mathrm{Cl})$. Environ. Sci. Technol. 47, 6855-6863. doi:10.1021/es400107n

Durst, R., Imfeld, G., Lange, J., 2013. Transport of pesticides and artificial tracers in vertical-flow labscale wetlands. Water Resour. Res. 49, 554-564. doi:10.1002/wrcr.20080

Eckert, D., Rolle, M., Cirpka, O. a., 2012. Numerical simulation of isotope fractionation in steady-state bioreactive transport controlled by transverse mixing. J. Contam. Hydrol. 140-141, 95-106. doi:10.1016/j.jconhyd.2012.08.010

Elsayed, O.F., Maillard, E., Vuilleumier, S., Nijenhuis, I., Richnow, H.H., Imfeld, G., 2014. Using compound-specific isotope analysis to assess the degradation of chloroacetanilide herbicides in labscale wetlands. Chemosphere 99, 89-95. doi:10.1016/j.chemosphere.2013.10.027 
Elsner, M., 2010. Stable isotope fractionation to investigate natural transformation mechanisms of organic contaminants: principles, prospects and limitations. J. Environ. Monit. 12, 2005-2031. doi:10.1039/c0em00277a

Elsner, M., Zwank, L., Hunkeler, D., Schwarzenbach, R.P., 2005. A new concept linking observable stable isotope fractionation to transformation pathways of organic pollutants. Environ. Sci. Technol. 39, 6896-6916. doi:10.1021/es0504587

Fenner, K., Canonica, S., Wackett, L.P., Elsner, M., 2013. Evaluating pesticide degradation in the environment: blind spots and emerging opportunities. Science 341, 752-8. doi:10.1126/science.1236281

Hartenbach, A.E., Hofstetter, T.B., Tentscher, P.R., Canonica, S., Berg, M., Schwarzenbach, R.P., 2008. Carbon, Hydrogen, and Nitrogen Isotope Fractionation During Light-Induced Transformations of Atrazine. Environ. Sci. Technol. 42, 7751-7756. doi:10.1021/es800356h

Hofstetter, T.B., Reddy, C.M., Heraty, L.J., Berg, M., Sturchio, N.C., 2007. Carbon and chlorine isotope effects during abiotic reductive dechlorination of polychlorinated ethanes. Environ. Sci. Technol. 41, 4662-4668. doi:10.1021/es0704028

Hofstetter, T.B., Spain, J.C., Nishino, S.F., Bolotin, J., Schwarzenbach, R.P., 2008. Identifying competing aerobic nitrobenzene biodegradation pathways by compound-specific isotope analysis. Environ. Sci. Technol. 42, 4764-4770. doi:10.1021/es8001053

Holtze, M.S., Sørensen, S.R., Sørensen, J., Aamand, J., 2008. Microbial degradation of the benzonitrile herbicides dichlobenil, bromoxynil and ioxynil in soil and subsurface environments - Insights into degradation pathways, persistent metabolites and involved degrader organisms. Environ. Pollut. doi:10.1016/j.envpol.2007.09.020

Hunkeler, D., Van Breukelen, B.M., Elsner, M., 2009. Modeling chlorine isotope trends during sequential transformation of chlorinated ethenes. Environ. Sci. Technol. 43, 6750-6756. doi:10.1021/es900579z

Imfeld, G., Lefrancq, M., Maillard, E., Payraudeau, S., 2013. Transport and attenuation of dissolved glyphosate and AMPA in a stormwater wetland. Chemosphere 90, 1333-1339. doi:10.1016/j.chemosphere.2012.04.054

Imfeld, G., Vuilleumier, S., 2012. Measuring the effects of pesticides on bacterial communities in soil: A critical review. Eur. J. Soil Biol. 49, 22-30. doi:10.1016/j.ejsobi.2011.11.010

Jin, B., Haderlein, S.B., Rolle, M., 2013. Integrated carbon and chlorine isotope modeling: Applications to chlorinated aliphatic hydrocarbons dechlorination. Environ. Sci. Technol. 47, 1443-1451. doi:10.1021/es304053h

Jin, B., Laskov, C., Rolle, M., Haderlein, S.B., 2011. Chlorine Isotope Analysis of Organic Contaminants Using GC-qMS: Method Optimization and Comparison of Different Evaluation Schemes. Environ. Sci. Technol. 45, 5279-5286. doi:10.1021/es200749d 
Jin, B., Rolle, M., 2014. Mechanistic approach to multi-element isotope modeling of organic contaminant degradation. Chemosphere 95, 131-139. doi:10.1016/j.chemosphere.2013.08.050

Jin, B., Rolle, M., Li, T., Haderlein, S.B., 2014. Diffusive fractionation of BTEX and chlorinated ethenes in aqueous solution: Quantification of spatial isotope gradients. Environ. Sci. Technol. 48, 61416150. doi:10.1021/es4046956

Kuder, T., Van Breukelen, B.M., Vanderford, M., Philp, P., 2013. 3D-CSIA: Carbon, chlorine, and hydrogen isotope fractionation in transformation of TCE to ethene by a dehalococcoides culture. Environ. Sci. Technol. 47, 9668-9677. doi:10.1021/es400463p

Lapworth, D.J., Baran, N., Stuart, M.E., Ward, R.S., 2012. Emerging organic contaminants in groundwater: A review of sources, fate and occurrence. Environ. Pollut. 163, 287-303. doi:10.1016/j.envpol.2011.12.034

Maier, M.P., De Corte, S., Nitsche, S., Spaett, T., Boon, N., Elsner, M., 2014. C \& N isotope analysis of diclofenac to distinguish oxidative and reductive transformation and to track commercial products. Environ. Sci. Technol. 48, 2312-2320. doi:10.1021/es403214z

Mckelvie, J.R., Elsner, M., Simpson, A.J., Lollar, B.S., Simpson, M.J., 2010. Quantitative site-specific 2H NMR investigation of MTBE: Potential for assessing contaminant sources and fate. Environ. Sci. Technol. 44, 1062-1068. doi:10.1021/es9030276

Meyer, A.H., Elsner, M., 2013. 13C/12C and 15N/14N isotope analysis to characterize degradation of atrazine: Evidence from parent and daughter compound values. Environ. Sci. Technol. 47, 68846891. doi:10.1021/es305242q

Murray, K.E., Thomas, S.M., Bodour, A. a., 2010. Prioritizing research for trace pollutants and emerging contaminants in the freshwater environment. Environ. Pollut. 158, 3462-3471. doi:10.1016/j.envpol.2010.08.009

Pal, A., Gin, K.Y.H., Lin, A.Y.C., Reinhard, M., 2010. Impacts of emerging organic contaminants on freshwater resources: Review of recent occurrences, sources, fate and effects. Sci. Total Environ. 408, 6062-6069. doi:10.1016/j.scitotenv.2010.09.026

Palau, J., Shouakar-Stash, O., Hunkeler, D., 2014. Carbon and Chlorine Isotope Analysis to Identify Abiotic Degradation Pathways of 1,1,1-Trichloroethane. Environ. Sci. Technol. 48, 14400-14408. doi:10.1021/es504252z

Penning, H., Sørensen, S.R., Meyer, A.H., Aamand, J., Elsner, M., 2010. C, N, and H Isotope Fractionation of the Herbicide Isoproturon Reflects Different Microbial Transformation Pathways. Environ. Sci. Technol. 44, 2372-2378. doi:10.1021/es9031858

Reinnicke, S., Simonsen, A., Sorensen, S.R., Aamand, J., Elsner, M., 2011. C and N Isotope Fractionation during Biodegradation of the Pesticide Metabolite 2,6- Dichlorobenzamide (BAM): Potential for Environmental Assessments. Environ. Sci. Technol. 46, 111216165921008. doi:10.1021/es203660g

Schwarzenbach, R.P., Egli, T., Hofstetter, T.B., von Gunten, U., Wehrli, B., 2010. Global Water Pollution and Human Health. Annu. Rev. Environ. Resour. doi:10.1146/annurev-environ-100809-125342 
Schwarzenbach, R.P., Escher, B.I., Fenner, K., Hofstetter, T.B., Johnson, C.A., von Gunten, U., Wehrli, B., 2006. The challenge of micropollutants in aquatic systems. Science 313, 1072-1077. doi:10.1126/science.1127291

Thullner, M., Centler, F., Richnow, H.-H., Fischer, A., 2012. Quantification of organic pollutant degradation in contaminated aquifers using compound specific stable isotope analysis - Review of recent developments. Org. Geochem. 42, 1440-1460. doi:10.1016/j.orggeochem.2011.10.011

Van Breukelen, B.M., Rolle, M., 2012. Transverse hydrodynamic dispersion effects on isotope signals in groundwater chlorinated solvents plumes. Environ. Sci. Technol. 46, 7700-7708. doi:10.1021/es301058z

Vorkamp, K., Bossi, R., Bester, K., Bollmann, U.E., Boutrup, S., 2014. New priority substances of the European Water Framework Directive: Biocides, pesticides and brominated flame retardants in the aquatic environment of Denmark. Sci. Total Environ. 470-471, 459-468. doi:10.1016/j.scitotenv.2013.09.096

Wuerfel, O., Greule, M., Keppler, F., Jochmann, M. a., Schmidt, T.C., 2013. Position-specific isotope analysis of the methyl group carbon in methylcobalamin for the investigation of biomethylation processes. Anal. Bioanal. Chem. 405, 2833-2841. doi:10.1007/s00216-012-6635-x

Zhang, N., Bashir, S., Qin, J., Schindelka, J., Fischer, A., Nijenhuis, I., Herrmann, H., Wick, L.Y., Richnow, H.H., 2014. Compound specific stable isotope analysis (CSIA) to characterize transformation mechanisms of $\alpha$-hexachlorocyclohexane. J. Hazard. Mater. 280, 750-757. doi:10.1016/j.jhazmat.2014.08.046 